\title{
COVID-19-related acute respiratory distress syndrome treated with veno-venous extracorporeal membrane oxygenation and programmed multi-level ventilation: a case report
}

\author{
Filip Depta ${ }^{1,2}$, Anton Turčan ${ }^{3}$, Pavol Török ${ }^{1,2}$, Petra Kapral'ová ${ }^{1,2}$, Michael A. Gentile ${ }^{4}$ \\ ${ }^{1}$ Department of Critical Care, East Slovak Institute of Cardiovascular Diseases, Košice; ${ }^{2}$ Medical Faculty, Pavol Jozef Šafárik University, Košice, ${ }^{3}$ Department of \\ Critical Care, University Hospital J.A. Reiman, Prešov, Slovak Republic;' Respiratory Care Services, Duke University Medical Center, Durham, NC, USA
}

We report a patient with severe coronavirus disease 2019 (COVID-19) acute respiratory distress syndrome (ARDS) treated with veno-venous extracorporeal membrane oxygenation (W ECMO) and programmed multi-level ventilation (PMLV). W ECMO as a treatment modality for severe ARDS has been described multiple times as a rescue therapy for refractory hypoxemia. It is well known that conventional ventilation can cause ventilator-induced lung injury. Protective ventilation during W ECMO seems to be beneficial, translating to using low tidal volumes, prone positioning with general concept of open lung approach. However, mechanical ventilation is still required as ECMO per se is usually not sufficient to maintain adequate gas exchange due to hyperdynamic state of the patient and limitation of blood flow via W ECMO. This report describes ventilation strategy using PMLV during "resting" period of the lung. In short, PMLV is a strategy for ventilating non-homogenous lungs that incorporates expiratory time constants and multiple levels of positive end-expiratory pressure. Using this approach, most affected acute lung injury/ARDS areas can be recruited, while preventing overdistension in healthy areas. To our knowledge, case report using such ventilation strategy for lung resting period has not been previously published.

Key Words: acute respiratory distress syndrome; COVID-19; programmed multi-level ventilation; veno-venous extracorporeal membrane oxygenation

The acute respiratory distress syndrome (ARDS) secondary to viral pneumonitis is one of the main causes of high mortality in patients with coronavirus disease 2019 (COVID-19) that has been estimated to be around 39\% [1]. Some patients develop refractory hypoxemia that necessitates utilization of veno-venous extracorporeal membrane oxygenation (VV ECMO) [2]. By substituting some of the lung's function in terms of oxygenation and $\mathrm{CO}_{2}$ removal, a common strategy applied is "lung resting" protective ventilation using lower ventilation pressures and tidal volumes (Vt; typically $<6 \mathrm{ml} / \mathrm{kg} /$ predicted body weight) to minimize ventilator-induced lung injury until lung function impairment resolves. Moreover, it has been shown that low driving pressure in ECMO patients with ARDS is associated with reduced mortality

\section{Case Report}

Received: August 19, 2021

Revised: September 28, 2021

Accepted: October 5, 2021

\section{Corresponding author}

Filip Depta

Department of Critical Care, East

Slovak Institute of Cardiovascular

Diseases, Ondavská 8, Košice, 040 11,

Slovak Republic

Tel: +421-9-4850-7269

E-mail: fdepta@protonmail.com

Copyright @ 2022 The Korean Society of Critical Care Medicine

This is an Open Access article distributed under the terms of Creative Attributions Non-Commercial License (https://creativecommons.org/li-censes/by-nc/4.0/) which permits unrestricted noncommercial use, distribution, and reproduction in any medium, provided the original work is properly cited. 
[3]. Lung rest can also be achieved by more physiological approach to protective ventilation.

Programmed multi-level ventilation (PMLV) ventilation strategy has already been described as a superior method for lung recruitment in heart surgery [4]. It is based on measured first expiratory time constant (TauE) to calculate optimal frequency in order to minimize intrinsic positive end-expiratory pressure (PEEPi). Additionally, alternating PEEP levels may allow ventilation of most diseased lung regions and provide recruitment (Figure 1). Changing two or three PEEP levels enable redistribution of a part of Vt into diseased compartments while protecting healthy areas from overdistension.

\section{CASE REPORT}

A 56-year-old female presented to the intensive care unit with shortness of breath, non-productive dry cough and worsening hypoxemia ( $\mathrm{SpO}_{2}$ at admission of $70 \%$ on room air). Her medical history included hypertension, obesity (body mass index, $40.2 \mathrm{~kg} / \mathrm{m}^{2}$ ) and stable bronchial asthma. Severe acute respi- ratory syndrome coronavirus 2 (SARS-CoV-2) COVID-19 test was positive via polymerase chain reaction test. Improvement of oxygenation was attempted initially by total face continuous positive airway pressure ventilation mask with $0.5 \mathrm{FiO}_{2}$ (Total Face DiMax; Dimar Medical Devices, Medolla, Italy) but did not yield improvement. She was intubated and mechanical ventilation was initiated using Bilevel mode (Puritan Bennett 840; Medtronic, Minneapolis, MN, USA) that also proved ineffective (PEEP high [PEEP $]$ ], 28; PEEP low [PEEP low $_{\text {] }}$, $14 \mathrm{~cm} \mathrm{H}_{2} \mathrm{O}$; inspiratory: to expiratory ratio, 1:1; PEEP plat $\left[\mathrm{P}_{\text {plat }}\right], 30 \mathrm{~cm} \mathrm{H}_{2} \mathrm{O}$; $\mathrm{Vt}, 420 \mathrm{ml} ; \mathrm{FiO}_{2}, 0.8$ ) despite using prone positioning. Two days later, her condition worsened by reaching $\mathrm{PaO}_{2}$ to $\mathrm{FiO}_{2}$ ratio of 75 according to Berlin ARDS criteria $\left(\mathrm{PaO}_{2}, 60 \mathrm{~mm} \mathrm{Hg} ; \mathrm{FiO}_{2}, 0,8\right.$; PEEP, $10 \mathrm{~cm} \mathrm{H}_{2} \mathrm{O}$; Pplat, $35 \mathrm{~cm} \mathrm{H}_{2} \mathrm{O}$ ) (Figure 2A). Calculated Murray score for acute lung injury was 3.3 with a corresponding predicted mortality of $45 \%$. Therefore, ECMO center was consulted and patient transferred.

VV ECMO (Cardiohelp System; Maquet Cardiopulmonary, Hirrlingen, Germany) was initiated using 19-Fr inflow canula inserted via right common femoral vein, and 17-Fr outflow
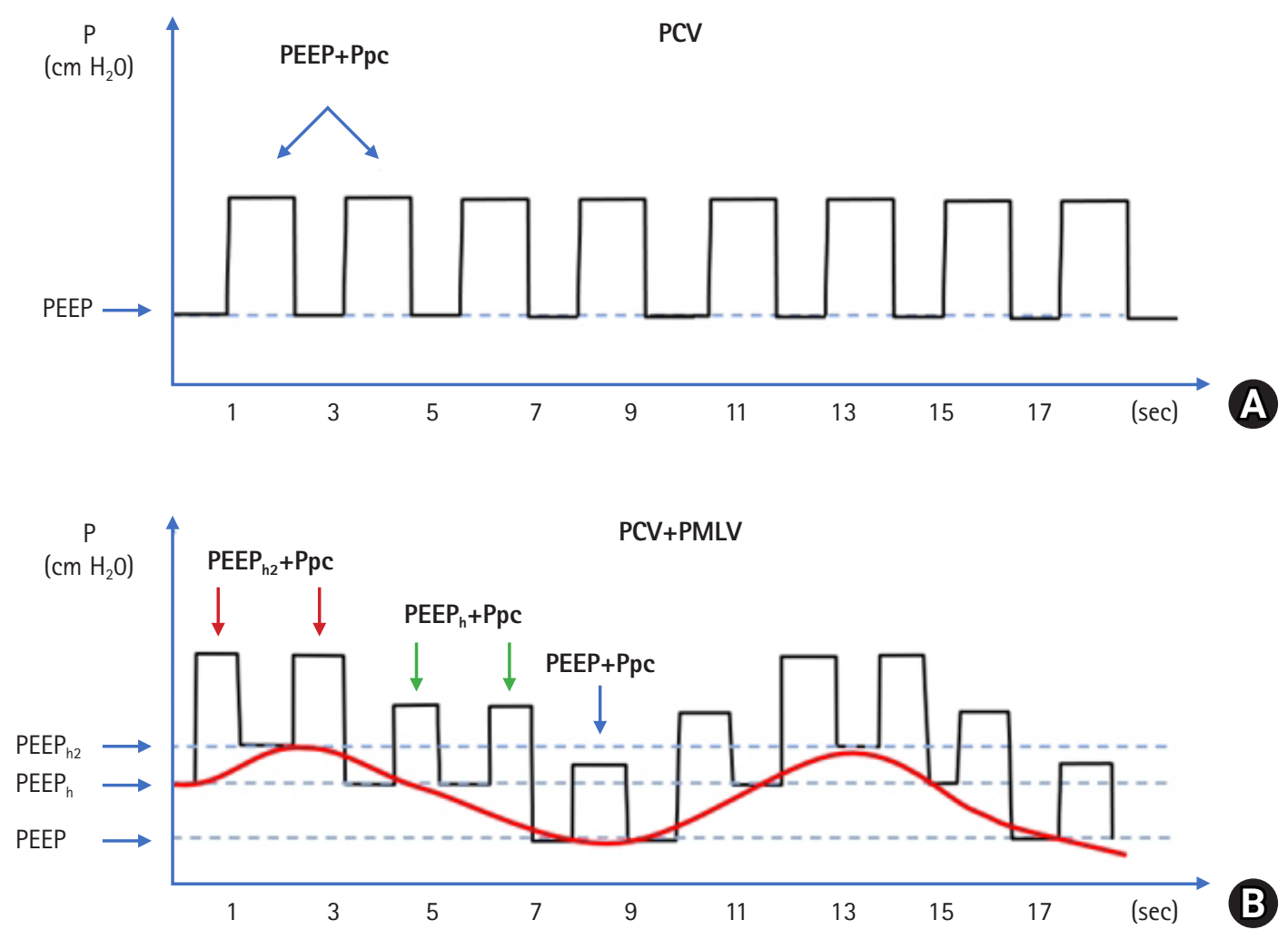

Figure 1. Schematic representation of pressure vs. time curve scheme when pressure controlled ventilation (PCV) ventilation (A) and programmed multi-level ventilation (PMLV) is activated on top of PCV (B). PEEP: positive end-expiratory pressure; PEEP ${ }_{h}$ : PEEP high; PEEP ${ }_{h 2}$ : PEEP high2; Ppc: pressure of pressure control. 

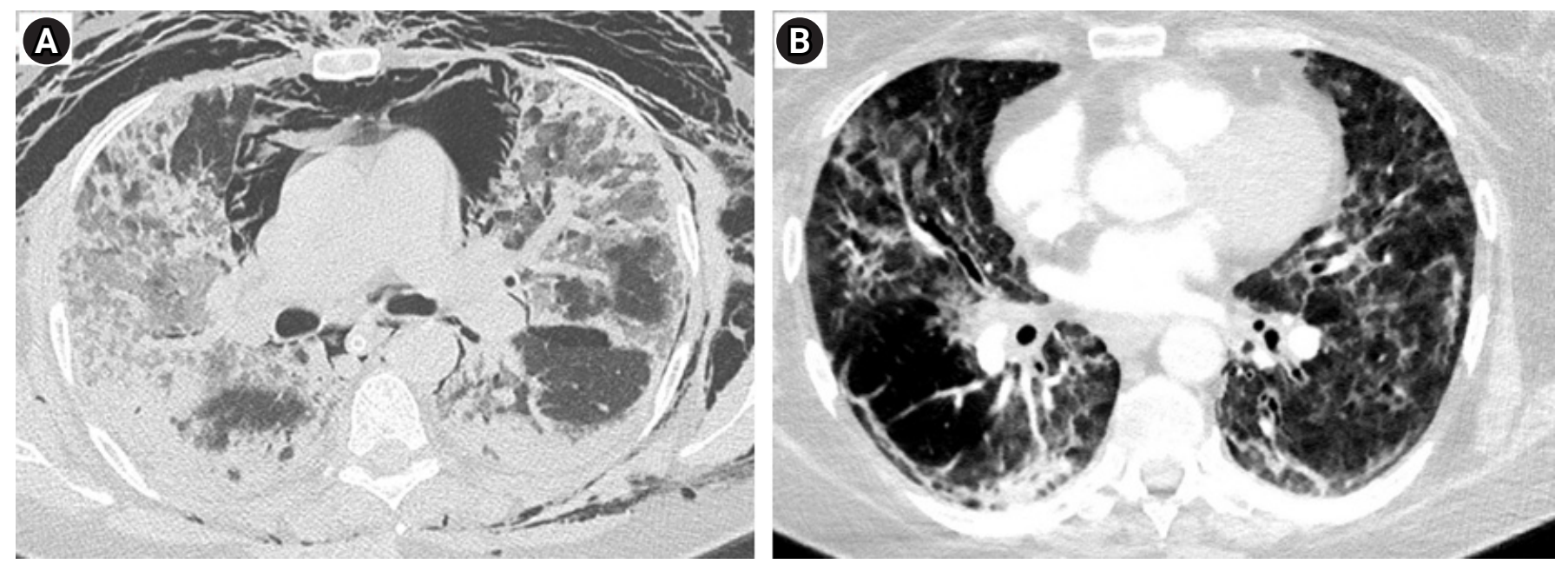

Figure 2. Computed tomography (CT) scan showing classical appearance of acute phase acute respiratory distress syndrome with pneumomediastinum on Bi-Level ventilation at admission (day 1, A) and CT scan after weaning from programmed multi-level ventilation (day 14, B).

canula inserted via left internal jugular vein, with initial VV ECMO flow of $4 \mathrm{~L} / \mathrm{min}$. Institutional anticoagulation protocol was initiated and maintained using unfractionated heparin (UFH), aiming for aiming for activated partial thromboplastin time of 60-80 seconds for the whole time on ECMO. While on ECMO, the patient was returned into prone position. After proning, pulmonary mechanics were measured including dynamic expiratory TauE and lung rest strategy was started using pressure controlled ventilation (PCV) and PMLV mode with an Aura V ventilator (Chirana Medical, Stará Turá, Slovakia). Initially four levels PMLV (4LV PMLV with three alternating PEEP levels with PC on top of each PEEP) and later three levels (3LV PMLV with two levels of changing PEEP with PC atop of each PEEP) was used. Initial settings with 4LV PMLV were: respiratory rate (RR) of 30/min, PEEP $8 \mathrm{~cm} \mathrm{H}_{2} \mathrm{O}, \mathrm{PEEP}_{\mathrm{h}} 5 \mathrm{~cm} \mathrm{H}_{2} \mathrm{O}$ and PEEP $_{\mathrm{h} 2} 5 \mathrm{~cm} \mathrm{H}_{2} \mathrm{O}$ with $\mathrm{PEEP}_{\mathrm{h}}$ being used in $50 \%$ of all respiratory cycles and $\mathrm{PEEP}_{\mathrm{h} 2}$ in $25 \%$ of all respiratory cycles. PC was used atop of all PEEP levels with peak inspiratory pressure not exceeding $30 \mathrm{~cm} \mathrm{H}_{2} \mathrm{O}$.

On day 4 , the patient was bleeding from puncture sites, with profound thrombocytopenia (from 130,00 to $45,000 / \mu \mathrm{l}$ ) and disseminated intravascular coagulopathy diagnosed. Multiple transfusions and substitution of coagulation factors were required and anticoagulation with UFH stopped. On day 10, pulmonary mechanics markedly improved and VV ECMO successfully explanted. She was extubated on the same day passing gas exchange and neurological criteria. However, neurologic status suddenly worsened few hours after extubation including quadriplegia and aphasia, with preserved eye move- ments only, that resembled locked-in syndrome. Subsequent computed tomography angiography showed basilar artery thrombosis with poor peripheral flow to adjacent arteries. Mechanical thrombectomy was performed and blood flow was restored, but catheter manipulation near sensitive areas of the brainstem caused circulatory arrest that necessitated intubation and cardiopulmonary resuscitation for 5 minutes which resulted in hemodynamic stability.

During the next three days, she was on mechanical ventilation and unable to wean due in part to bacterial superinfection (Klebsiella pneumoniae) that necessitated frequent bronchoscopies. Pressure supported ventilation (PSV) mode with 3LV PMLV was used: RR 24/min, PEEP $8 \mathrm{~cm} \mathrm{H}_{2} \mathrm{O}, \mathrm{PEEP}_{\mathrm{h}} 6 \mathrm{~cm} \mathrm{H}_{2} \mathrm{O}$, with PEEP $_{\mathrm{h}}$ being used in $50 \%$ of all respiratory cycles. PSV was used on top of all PEEP levels with peak inspiratory pressure rarely exceeding $30 \mathrm{~cm} \mathrm{H}_{2} \mathrm{O}$. She was extubated on day 14 (Figure 2B), with neurologic status slowly returning to normal. At discharge she was neurologically intact, walking spontaneously with basic walking assistance device. She was transferred to an intensive rehabilitation facility of her own choosing a month after admission.

\section{DISCUSSION}

Optimal ventilation strategy during lung resting period with part of gas is exchanged extracorporeally, is heavily debated [5]. Ideal ventilation mode should prevent further damage to the lung, promote recovery and enable weaning from mechanical ventilation. The most frequent initial mode of ventilation used 
during ECMO is controlled (62\%), followed by supported (21\%) and APRV (4\%), with PCV being the preferred controlled mode of ventilation [6]. There are various goals for ventilating lungs on VV ECMO. Lung rest seems to be most widely used ventilation goal and lung recruitment is stated as a goal much less often [6].

PMLV may combine advantage of both, lung rest and recruitment at the same time, while including fundamentals of protective ventilation. PMLV is based on pulmonary physiology and measured, not calculated TauE. Based on TauE, optimal frequency can be set to achieve full exhalation, and thus avoiding PEEPi. PMLV operates with alternating different levels of PEEP. When using 2 PEEP levels, the ventilation is 3 level PMLV (3LV PMLV) and when 3 levels of PEEP are used (4LV PMLV) because PCV or PSV is used on top of each PEEP, thus counting for another level. PMLV operates with multiple mechanisms. First, by allowing long inspiration times during subsequent PEEP increase, the effect of recruitment may be more pronounced and sustained during whole time of using PMLV.

Second, the part of Vt is redistributed from short TauE into long TauE compartments in the ARDS lung. By redistributing a part of Vt, healthy areas may be less prone to overdistension. This is largely explained by longer inspiration times during PEEP shifts from baseline to higher PEEP levels allowing longer equilibration time between various TauE compartments. Therefore, different Vt at each PEEP will be delivered using multiple PEEP. This approach may in turn increase aeration of the ARDS lung.

The application of PMLV may be beneficial during resting period of the lung while on VV ECMO in terms of recruitment and fundamentals of protective ventilation (e.g. PEEP, low Vt a plateau pressures). This strategy requires further studies for patients with ARDS and receiving ECMO.

\section{CONFLICT OF INTEREST}

No potential conflict of interest relevant to this article was reported.

\section{ORCID}

Filip Depta

Anton Turčan

https://orcid.org/0000-0002-2854-0450

Pavol Török

Petra Kapral'ová

https://orcid.org/0000-0001-7944-594X

https://orcid.org/0000-0002-2678-1074

https://orcid.org/0000-0002-1441-6483

Michael A. Gentile

\section{AUTHOR CONTRIBUTIONS}

Visualization: FD, AT, PK. Writing-original draft: FD. Writingreview \& editing: PT, MAG.

\section{REFERENCES}

1. Hasan SS, Capstick T, Ahmed R, Kow CS, Mazhar F, Merchant HA, et al. Mortality in COVID-19 patients with acute respiratory distress syndrome and corticosteroids use: a systematic review and meta-analysis. Expert Rev Respir Med 2020;14:1149-63.

2. Shaefi S, Brenner SK, Gupta S, O'Gara BP, Krajewski ML, Charytan DM, et al. Extracorporeal membrane oxygenation in patients with severe respiratory failure from COVID-19. Intensive Care Med 2021;47:208-21.

3. Serpa Neto A, Schmidt M, Azevedo LC, Bein T, Brochard L, Beutel G, et al. Associations between ventilator settings during extracorporeal membrane oxygenation for refractory hypoxemia and outcome in patients with acute respiratory distress syndrome: a pooled individual patient data analysis: mechanical ventilation during ECMO. Intensive Care Med 2016;42:1672-84

4. Candik P, Kolesar A, Nosal M, Paulíny M, Sabol F, Donicova V, et al. Use of programmed multilevel ventilation as a superior method for lung recruitment in heart surgery. Int J Crit Care Emerg Med 2019;5:067.

5. Del Sorbo L, Goffi A, Goligher E, Fan E, Slutsky AS. Setting mechanical ventilation in ARDS patients during VV-ECMO: where are we? Minerva Anestesiol 2015;81:1369-76.

6. Marhong JD, Telesnicki T, Munshi L, Del Sorbo L, Detsky M, Fan E. Mechanical ventilation during extracorporeal membrane oxygenation: an international survey. Ann Am Thorac Soc 2014;11:956-61. 